\title{
Trabalhando a Problemática Ambiental ao Viés de Quadros Colaborativos Online: Uma Ação no Contexto Escolar
}

\author{
André Ricardo Theodoro Velho ${ }^{1}$, Joice Maurell ${ }^{1}$, Regina Barwaldt ${ }^{1}$, Vagner Rosa ${ }^{1}$ \\ ${ }^{1}$ Centro de Ciências Computacionais - Universidade Federal do Rio Grande (FURG) \\ Av. Itália km 8 - 96.201-900 - Campus Carreiros - Rio Grande - RS - Brasil \\ \{andre.theodorodfurg.br, maurel15eyahoo.com.br, \\ reginabarwaldt@furg.br, vsrosa@gmail.com
}

\begin{abstract}
This article aims to promote environmental awareness, regarding the incorrect disposal of medicines by the general population. For this purpose, was built and implemented an Action at School Project, in which students engaged in local awareness activities, using online collaborative frameworks. From the research carried out by students, was detected the result that $82 \%$ of respondents are unaware of the problem of drug disposal. It was concluded that the practice performed and concepts covered were efficient to promote the following categories: environmental awareness, environmental impacts, the use of ICT for awareness and care and use.
\end{abstract}

Resumo. O presente artigo tem como objetivo promover a consciência ambiental, no que tange o descarte incorreto de medicamentos pela população em geral. Com esse objetivo, fora desenvolvido e aplicado um Projeto de Ação na Escola, no qual os estudantes envolveram-se em atividades de conscientização local, utilizando-se de quadros colaborativos online. A partir da pesquisa realizada, pelos estudantes, detectou-se o resultado que $82 \%$ dos entrevistados desconhecem a problemática do descarte de medicamentos. Concluiu-se, que a prática realizada e os conceitos abordados foram eficientes para promover as seguintes categorias: sensibilização ambiental, impactos ambientais, uso de TIC para conscientização e cuidado e utilização.

\section{Introdução}

A produção e consumo de medicamentos são as responsáveis pelas maiores movimentações financeiras no mundo, segundo o IMS Health ${ }^{1}$, o mercado de medicamentos irá alcançar cerca de US\$ 1,2 trilhões em 2016. Ainda segundo o Instituto IMS Health, o Brasil ocupa o $4^{\circ}$ mercado de consumo de medicamentos no mundo, sendo que estes dados nos levam a seguinte reflexão: tal fabricação de medicamentos pode vir a provocar um amplo acúmulo de resíduos farmacológicos dispensáveis e para onde vão tais substâncias?

Os medicamentos, ao serem descartados em locais inadequados, como vasos sanitários ou pias, se dissolvem formando uma mancha tóxica. Os descartados em lixos domésticos podem entrar em contato com outros seres humanos, contaminando-os, já no lixão ou aterro sanitário são transformados em poluentes e em uma substância tóxica,

\footnotetext{
1 IMS Health é uma Consultora Internacional de Marketing Farmacêutico responsável por auditar o mercado farmacêutico mundial.
} 
V Congresso Brasileiro de Informática na Educação (CBIE 2016)

Anais do XXII Workshop de Informática na Escola (WIE 2016)

chamada chorume, que pode infectar ao mesmo tempo o solo, o lençol freático, os rios e a atmosfera [MARQUEZOTI et al., 2016; BRASIL, 2010].

Ambos, ao contaminarem a água, percorrem pela rede de esgotos da cidade até c)hegar a uma estação de tratamento, no caso de cidades que possuam esse serviço. A mancha tóxica de remédios não é tratada como o esgoto normal, pois a mesma, necessita de um processo especial, que não ocorre na estação de tratamento. Da estação de tratamento, os resíduos farmacológicos não tratados, são liberados em rios, lagos e mares, agravando assim, a poluição no meio ambiente [MARQUEZOTI et al., 2016; BRASIL, 2010].

Hoje no Brasil existe uma grande diversidade de regulamentações e iniciativas nos estados e municípios de recolhimento, devolução, doação e descarte de resíduos de medicamentos pela população. Isso se deve ao fato de ainda não se ter uma regulamentação específica no âmbito nacional relacionada ao descarte e destinação final ambientalmente adequada de resíduos de medicamentos descartados pela população [MARQUEZOTI et al., 2016; BRASIL, 2010].

A Agência Nacional de Vigilância Sanitária² (ANVISA), por sua vez, utiliza-se da Lei $\mathrm{n}^{\circ}$. 12.305, de 2 de agosto de 2010, que institui a Política Nacional de Resíduos Sólidos, com a finalidade de preservar a saúde pública e proteger e melhorar a qualidade do meio ambiente. Esta lei, também, torna-se integrante da Política Nacional do Meio Ambiente e articula-se com a Política Nacional de Educação Ambiental, regulada pela Lei no 9.795, de 27 de abril de 1999, com a Política Federal de Saneamento Básico, regulada pela Lei $\mathrm{n}^{\mathrm{o}} 11.445$, de 2007, e com a Lei $\mathrm{n}^{\mathrm{o}}$. 11.107, de 6 de abril de 2005 [BRASIL, 2010].

Com o objetivo de contextualizar as ações em um espaço escolar, foi desenvolvido e aplicado um Projeto de Ação na Escola (PAE) para fomentar o processo de educação ambiental local e, também, discutir a problemática sócio-ambiental do descarte de medicamentos de forma incorreta. Através de uma abordagem de ensino e aprendizagem construtivista, alicerçada na metodologia de ensino Unidades de Aprendizagem (UA), nos utilizamos das Tecnologias da Informação e Comunicação (TIC) para desenvolver quadros colaborativos online, nos quais os estudantes puderam levantar as questões estudadas dentro do contexto escolar e compartilhar as informações com outras pessoas.

O artigo está organizado da seguinte forma: na Seção 2 temos o referencial teórico que dá suporte as práticas pesquisadas, discutindo a Educação Ambiental, Inteligência Coletiva, Ciberespaço e Cibercultura, Unidades de Aprendizagem e Plataforma de Quadros Colaborativos Online: Padlet. A Seção 3 apresenta a metodologia de trabalho empregada, seguido, pela Seção 4 que expõem as reflexões inerentes a análise dos resultados encontrados. Por fim, na Seção 5 apontamos as considerações finais da pesquisa realizada.

\footnotetext{
${ }^{2}$ Criada pela Lei no 9.782, de 26 de janeiro 1999, a Agência Nacional de Vigilância Sanitária (Anvisa) é uma autarquia sob regime especial, que tem como área de atuação não um setor específico da economia, mas todos os setores relacionados a produtos e serviços que possam afetar a saúde da população brasileira.
} 
V Congresso Brasileiro de Informática na Educação (CBIE 2016)

Anais do XXII Workshop de Informática na Escola (WIE 2016)

\section{Referencial Teórico}

\subsection{Educação Ambiental}

Um dos fatores que tornam a EA um dos temas mais importantes e debatidos na área educacional da atualidade é a sua abordagem interdisciplinar, que permite que diferentes conceitos, assuntos e temáticas sejam abordados à luz da Educação Ambiental e nos mais diversos níveis de educação. Somando a isto, o crescimento constante da consciência de preservação ambiental e do agir sustentável em todas as formas de relação com o ambiente e o outro, admitem que esta temática seja explorada em diferentes debates acadêmicos, nos mais diversos campos do conhecimento [MEIRA et al, 2015].

Neste ponto, se fez necessário definirmos a nossa própria visão do que é sustentabilidade e no que se baseia o agir sustentável. Na literatura encontramos diversos autores que abordam este assunto implicando seu entendimento com dimensões políticas, sociais, culturais e biológicas, permeando desta forma, uma constante produção e difusão de modo transdisciplinar de conceitos que definem a sustentabilidade e seu agir [REIGOTA, 2007]. Assumimos então, sustentabilidade como ações e atividades humanas que tendem prover as necessidades hodiernas dos seres humanos, sem danificar o futuro das próximas gerações, de tal forma que, a sustentabilidade está absolutamente conexa ao desenvolvimento material e econômico sem agredir o meio ambiente, utilizando os recursos naturais de forma inteligente, para que eles se conservem e existam no futuro [REIGOTA, 2007].

\subsection{Inteligência Coletiva, Ciberespaço e a Cibercultura}

A construção do conhecimento não precisa ser uma atividade individualizada e solitária, o pesquisador e escritor francês Pierre Lévy (2003) teoriza a respeito do que ele chama de Inteligência Coletiva (IC) que é, essencialmente, o compartilhamento das funções cognitivas, como por exemplo, a memória, a percepção e o aprendizado. Embasados na teoria de Lévy entendemos que o aprendizado pode ser compartilhado, através do meio, com os outros que integram este meio.

A inteligência coletiva é um tema de abordagem interdisciplinar, o que permite, que o mesmo seja explorado pelas mais diversas áreas do conhecimento. O tema, ainda, está claramente vinculado ao momento tecnológico digital que vivemos em nossa contemporaneidade, ao qual, Lévy denomina como ciberespaço. Ao que tange ao ciberespaço, o autor, entende que o mesmo vai além de um meio de mídia ou comunicação, tornando-se um espaço de reunião de diversificadas mídias e interfaces, que podem ser desde mídias tradicionais, como revistas, jornais, TV, etc., tangendo também, diferentes interfaces que permitam a interação ao mesmo tempo ou não, como o caso de chats, blogs, fóruns de discussão, entre outros [LÉVY, 2003].

Tais conceitos nos auxiliam a compreender que o ciberespaço é um local propício para que a inteligência coletiva se forme através da interação entre as pessoas, pois seus conhecimentos individuais, podem ser compartilhados com a coletividade e saberes trocados, questionados e aprimorados, por meio de comunidades virtuais que possibilitem amplas conexões entre seus participantes. $\mathrm{O}$ autor conceitua a cibercultura exatamente como resultado da transmissão e construção de ideias através do ciberespaço, onde, ele complementa seu entendimento, afirmando, que a cibercultura é um movimento social e cultural que apresenta novas formas e possibilidades de aprender e ensinar [LÉVY, 2003]. 
Ao adotarmos os conceitos de inteligência coletiva, ciberespaço e cibercultura como um fato concreto em nossa contemporaneidade, assumimos que é possível aprender e ensinar a partir deles, fazendo com que, as ações de interação entre os usuários desses espaços sejam capazes de construir sólidos conhecimentos nos envolvidos, e não só isso, mas fazer também, com que eles sejam capazes de compartilhar suas descobertas.

\subsection{Unidades de Aprendizagem}

Em busca de uma metodologia de aprendizagem que fomentasse as ações realizadas encontramos nas Unidades de Aprendizagem (UA) o elo que necessitávamos para a estruturação de um PAE que permeasse a educação ambiental, a inteligência coletiva, o ciberespaço e a cibercultura. Isto porque a UA é uma metodologia de ensino construtivista, que apresenta um modo alternativo do planejamento, da elaboração e da organização da forma como serão realizados os trabalhos dentro da sala de aula [GALIAZZI et al, 2004].

Outro ponto que fundamenta o uso de UA é sua abrangência no planejamento de aulas que potencializa o trabalho interdisciplinar, que são originários das possibilidades de participação e integração de estudantes e professores de diferentes áreas [GALIAZZI et al, 2004]. Estando, também, de acordo com a Educação Ambiental, que propícia esse cenário de interdisciplinaridade. Sendo que, a UA se faz em conjunto e em permanente processo, o que lhe dá o tom, de uma estrutura que não está engessada, sendo sim, algo flexível, dinâmico, investigativo que será norteado durante seu planejamento, produção e desenvolvimento [GALIAZZI et al, 2004].

\subsection{Plataforma de Quadros Colaborativos Online: Padlet}

O Padlet ${ }^{3}$ é uma plataforma online colaborativa que possibilita aos seus usuários a criação de murais virtuais, também chamados de quadros, que permitem com que os utilizadores expressem suas ideias, opiniões de maneira fácil e ágil, simulando uma folha de papel. $\mathrm{O}$ usuário tem a opção de postar qualquer tipo de conteúdo, textos, imagens, vídeos, áudios, hiperlinks de forma colaborativa, ou seja, várias pessoas podem trabalhar ao mesmo tempo em um mesmo quadro.

A ferramenta permite que o usuário crie uma conta e, a partir desta, passa a ter privacidades, tal qual, que somente os convidados, via e-mail ou por senha, possam acessar e colaborar na construção do quadro online. O mural público, permite que o mesmo seja indexado nas buscas do Google.

Ainda nas configurações do quadro colaborativo há a possibilidade de se criar um endereço, que será a forma, utilizada para que terceiros acessem o mural, e que o mesmo, seja compartilhado nas mais diferentes redes sociais. A ferramenta possui diversos tutoriais que auxiliam no entendimento da utilização da mesma.

As possibilidades de usabilidade na coletividade, assim como, o uso de diversas mídias em um formato de fácil interação, fizeram com que o Padlet fosse a ferramenta escolhida para o Projeto de Ação na Escola. Os quadros colaborativos online justificam o apelo à geração do século XXI, que visualizam nas mídias sociais uma forma de se expressarem.

\footnotetext{
${ }^{3}$ Site: https://padlet.com/
} 
V Congresso Brasileiro de Informática na Educação (CBIE 2016)

Anais do XXII Workshop de Informática na Escola (WIE 2016)

\section{Metodologia}

A instituição escolhida para aplicação do PAE foi uma escola de ensino profissionalizante, que oferta diversos cursos de formação inicial e continuada (FIC). O PAE foi aplicado em uma turma do curso de Informática Fundamental, não sendo atrelada há um módulo específico do curso, mas tornando-se interdisciplinar ao utilizar-se de conhecimentos e práticas que perfaziam conteúdos programáticos de diferentes módulos de ensino. Os estudantes do curso possuem uma faixa etária entre quatorze e dezessete anos, escolaridade homogêneas e de diferentes etnias.

A oficina do PAE foi planejada contendo cinco etapas que ocorreram em dez dias, sendo que, cada encontro possuía três horas e vinte minutos de hora aula. O curso de Informática Fundamental foi ministrado durante a semana, no qual a oficina foi realiza no período de duas semanas, somando 32 horas de ações, divididas, em 3 horas e 20 minutos por aula. Um cronograma que evidência o formato de aplicação das atividades foi planejado elucidando cada etapa que deveria ser seguida, como visto, na tabela 1 a seguir.

Tabela 1. Cronograma da Aplicação do PAE

\begin{tabular}{|c|c|c|}
\hline Aula & $\begin{array}{l}\text { Gênero (s) Adotado } \\
\text { (s) }\end{array}$ & Objetivos / Observações \\
\hline $\begin{array}{l}1^{\circ} \text { Etapa - } \\
\text { Presencial }\end{array}$ & $\begin{array}{l}\checkmark \text { Metodologia } \\
\text { Construtivista UA }\end{array}$ & $\begin{array}{l}\checkmark \text { Abordagem dos assuntos propostos da Educação Ambiental } \\
\text { utilizando-se do planejamento de Unidades de Aprendizagem. } \\
\checkmark \text { Apresentação da plataforma Padlet e formas de utilização } \\
\text { para desenvolvimento de um projeto colaborativo de } \\
\text { Conscientização do Descarte Correto de Medicamentos. }\end{array}$ \\
\hline $\begin{array}{l}2^{\circ} \quad \text { Etapa }- \\
\text { Presencial com } \\
\text { possibilidades de } \\
\text { atividades a } \\
\text { distância devido } \\
\text { a mobilidade }\end{array}$ & $\begin{array}{l}\checkmark \text { Coleta de dados } \\
\checkmark \text { UA } \\
\checkmark \text { Alimentação da } \\
\text { plataforma }\end{array}$ & $\begin{array}{l}\checkmark \text { Login para cada estudante, possibilitando dessa forma, o } \\
\text { acesso ao quadro colaborativo online criado no Padlet. } \\
\checkmark \text { Debates e pesquisas norteados através da Unidades de } \\
\text { Aprendizagem. } \\
\checkmark \text { Pesquisa junto a população local sobre o conhecimento da } \\
\text { necessidade do descarte de medicamentos de forma correta. } \\
\checkmark \text { Pesquisa de locais de dispensa de medicamentos, assim } \\
\text { como, identificar quantos e quais a cidade possuem e formas } \\
\text { de divulgar esses locais, abrangendo, os perigos da } \\
\text { dispensação destes resíduos no meio ambiente. } \\
\checkmark \text { Inserção de dados na plataforma Padlet. }\end{array}$ \\
\hline $\begin{array}{l}3^{\circ} \quad \text { Etapa - } \\
\text { Presencial com } \\
\text { possibilidades de } \\
\text { atividades a } \\
\text { distância devido } \\
\text { a mobilidade }\end{array}$ & $\begin{array}{l}\checkmark \text { Coleta de dados } \\
\checkmark \text { Alimentação da } \\
\text { plataforma } \\
\checkmark \text { UA }\end{array}$ & $\begin{array}{l}\checkmark \text { Elaboração de gráficos e outras mídias para embasar os } \\
\text { dados coletados. } \\
\checkmark \text { Inserção de dados na plataforma Padlet. } \\
\checkmark \text { Elaboração de uma apresentação do projeto aos demais } \\
\text { estudantes da escola. }\end{array}$ \\
\hline $\begin{array}{l}4^{\circ} \quad \text { Etapa - } \\
\text { Presencial com } \\
\text { possibilidades de } \\
\text { atividades a } \\
\text { distância devido } \\
\text { a mobilidade }\end{array}$ & $\begin{array}{l}\checkmark \text { Alimentação da } \\
\text { plataforma } \\
\checkmark \text { Palestra sobre o } \\
\text { projeto para os demais } \\
\text { estudantes } \\
\checkmark \text { UA }\end{array}$ & $\begin{array}{l}\checkmark \text { Palestra sobre o projeto, realizada pelos estudantes e } \\
\text { mediada pelo professor, na escola de aplicação da oficina. Com } \\
\text { o intuito de tornar os estudantes multiplicadores da } \\
\text { problemática levantada. } \\
\checkmark \text { Inserção de dados na plataforma Padlet. }\end{array}$ \\
\hline
\end{tabular}


V Congresso Brasileiro de Informática na Educação (CBIE 2016)

Anais do XXII Workshop de Informática na Escola (WIE 2016)

\begin{tabular}{|c|c|c|c|}
\hline $5^{\circ} \quad$ Etapa - & & & $\checkmark$ Avaliação da UA. \\
\hline $\begin{array}{l}\text { Presencial com } \\
\text { possibilidades de } \\
\text { atividades a } \\
\text { distância devido } \\
\text { a mobilidade }\end{array}$ & $\begin{array}{l}\checkmark \text { Finalização } \\
\text { projeto }\end{array}$ & do & $\begin{array}{l}\checkmark \text { Finalização do projeto: o projeto na verdade não se encerra, } \\
\text { os quadros colaborativos no Padlet receberão a sugestão de } \\
\text { continuarem a serem produzidas mesmo com o término da } \\
\text { oficina PAE. }\end{array}$ \\
\hline
\end{tabular}

O PAE iniciou-se conforme a primeira etapa da Tabela 1, com a apresentação de um vídeo ${ }^{4}$ que descrevia as circunstâncias da problemática abordada e contextualizava o assunto discutido pelos aprendizes. O vídeo permitiu que os estudantes entendessem a situação problema e opinassem sobre a mesma, contando relatos, de episódios que os mesmos haviam vivenciado referente ao descarte de medicamentos, conforme preza a UA quando se utiliza do conhecimento prévio do estudante para gerar novo conhecimento [MORAES et al, 2004]. Uma constatação inerente a este primeiro diálogo foi a percepção de que nenhum dos estudantes tinha conhecimento dos problemas ocasionados pelo descarte de forma incorreta dos supracitados.

Das muitas falas de cada estudante, mediadas pelo docente, foi estimulado que os aprendizes buscassem maiores informações através de uma pesquisa na $W e b$ e construíssem mapas mentais que permeassem as descobertas realizadas. Conjuntamente, a plataforma Padlet foi apresentada aos estudantes, assim como, suas funcionalidades e potencialidades. A ideia de criação de um quadro colaborativo online alimentado pelos estudantes foi instigada neste momento, caracterizando o ciberespaço onde as atividades proporcionariam um campo fértil para a inteligência coletiva [LÉVY, 2003].

A segunda etapa iniciou-se com a criação do login na plataforma para que cada um dos estudantes tivesse acesso ao quadro colaborativo. Novas pesquisas permitiram diferentes debates que aprofundaram os conhecimentos dos estudantes sobre o meio ambiente, sustentabilidade e o agir sustentável. Duas pesquisas distintas foram iniciadas. A primeira prezava por um levantamento, junto a população local, da ciência quanto ao descarte correto de medicamentos. Já a segunda, prezava pelo levantamento de locais corretos para dispensa de medicamentos. Por fim, os estudantes iniciaram a alimentação da plataforma de maneira coletiva onde a cibercultura predominaria a forma de ensino e aprendizagem [LÉVY, 2003].

$\mathrm{Na}$ terceira etapa do PAE as pesquisas foram encerradas e os estudantes tiveram que tabular os dados obtidos e gerar gráficos, que por sua vez, alimentariam o quadro colaborativo. A terceira etapa ainda possibilitou aos estudantes descobrirem os locais corretos de descarte de medicamentos, quantos a cidade possui e definir formas de divulgação dos mesmos. Desta pesquisa os estudantes criaram um mapa da cidade com os principais pontos de coleta, assim como, propuseram formas de divulgação dessa necessidade ambiental. Todo o material gerado foi postado nos quadros colaborativos. Por fim, os estudantes desenvolveram uma apresentação para palestrarem sobre a problemática e explanarem as soluções e conhecimentos construídos no processo do PAE.

A quarta etapa contemplou a realização da palestra sobre a temática realizada pelos estudantes com a mediação do professor, desta forma, conscientizando a escola toda sobre os prejuízos do descarte incorreto de medicamentos e os locais adequados para o mesmo e divulgação dos quadros online criados. O arquivo da apresentação, assim como, relatos dos estudantes também foram postados na plataforma.

\footnotetext{
${ }^{4} \mathrm{https}: / /$ www.youtube.com/watch?v=938Y19rs1Z8
} 
A quinta etapa ocorreu em dois momentos, o primeiro, juntamente com os estudantes, o docente aconselhou que os mesmos poderiam continuar alimentado e divulgando os quadros colaborativos, mesmo com o término da oficina. Já o segundo momento, foi da elaboração de categorias que auxiliassem a avaliar o desenvolvimento pessoal e coletivo dos estudantes. Tais categorias foram elencadas dos quadros online conforme o número de posts que os aprendizes realizaram e/ou discutiram na plataforma.

\section{Análise dos Resultados}

A análise e levantamento dos resultados que são apresentados foram embasados em duas formas usuais de pesquisa científica, perfazendo deste modo, a pesquisa exploratória e a pesquisa descritiva [GIL, 2008]. A análise e discussão referidas a pesquisa exploratória envolvem o levantamento bibliográfico, entrevistas com pessoas que vivenciaram a prática com o problema pesquisado e a análise de exemplos que estimulem a compreensão. Já a pesquisa descritiva, por sua vez, preocupa-se com a utilização de técnicas padronizadas de coleta de dados e a observação sistemática do problema e do agir dos atores sobre o problema. [GIL, 2008].

Os dados foram analisados ao término da aplicação do PAE, permitindo assim, que pudéssemos explorar e investigar todas as ações ocorridas durante a oficina e elencar categorias que facilitassem a compreensão e a associação de ideias, concepções e percepções que os aprendizes desenvolveram durante a prática. As categorias foram elencadas através da análise dos quadros colaborativos e da codificação dos dados explorados, dessa forma, a repetição de palavras foram contrapostas com os conceitos norteadores que os estudantes desenvolveram na prática das atividades propostas, após o agrupamento de categorias iniciais e mais genéricas emergiu as categorias finais definidas e apresentadas na Tabela 2.

Tabela 2. Categorias

\begin{tabular}{ll}
\hline \multicolumn{1}{c}{ Categorias } & \multicolumn{1}{c}{ Conceitos Norteadores } \\
\hline $\begin{array}{l}\text { Sensibilização } \\
\text { Ambiental }\end{array}$ & $\begin{array}{l}\text { Percepção dos estudantes quanto o histórico e cenário atual do ambiente que os envolve. } \\
\text { Entendimento da gravidade que nossas ações podem gerar para a coletividade. Priorização } \\
\text { da conservação do meio ambiente buscando soluções que desenvolvam a qualidade de vida } \\
\text { sustentável da coletividade. Desenvolvimento do olhar sustentável. }\end{array}$ \\
\hline $\begin{array}{l}\text { Impactos } \\
\text { Ambientais }\end{array}$ & $\begin{array}{l}\text { Percepção dos impactos que o descarte incorreto de medicamentos pode ocasionar, como: } \\
\text { poluição da atmosfera; poluição de lençóis freáticos; poluição do solo; poluição de rios, } \\
\text { mares e lagos; }\end{array}$ \\
\hline $\begin{array}{l}\text { Uso de TIC para } \\
\text { Conscientização }\end{array}$ & $\begin{array}{l}\text { Entendimento das possibilidades que as Tecnologias da Informação e Comunicação geram, } \\
\text { através de suas ferramentas, no desenvolvimento de propostas de conscientização ambiental. }\end{array}$ \\
\hline $\begin{array}{l}\text { Cuidado } \\
\text { Utilização }\end{array}$ & $\begin{array}{l}\text { Percepção dos cuidados que devem ser tomados na manipulação de medicamentos e, } \\
\text { principalmente, nas formas de descarte dos mesmos. }\end{array}$ \\
\hline
\end{tabular}

As categorias finais contextualizam a síntese dos significados desenvolvidos pelos estudantes através da prática da oficina PAE. As supracitadas permitiram, também, a análise de tópicos das discussões emergentes e abrangidas pelos aprendizes nos quadros colaborativos, desta análise apresentamos as discussões mais promovidas pelos mesmos. 
V Congresso Brasileiro de Informática na Educação (CBIE 2016)

Anais do XXII Workshop de Informática na Escola (WIE 2016)

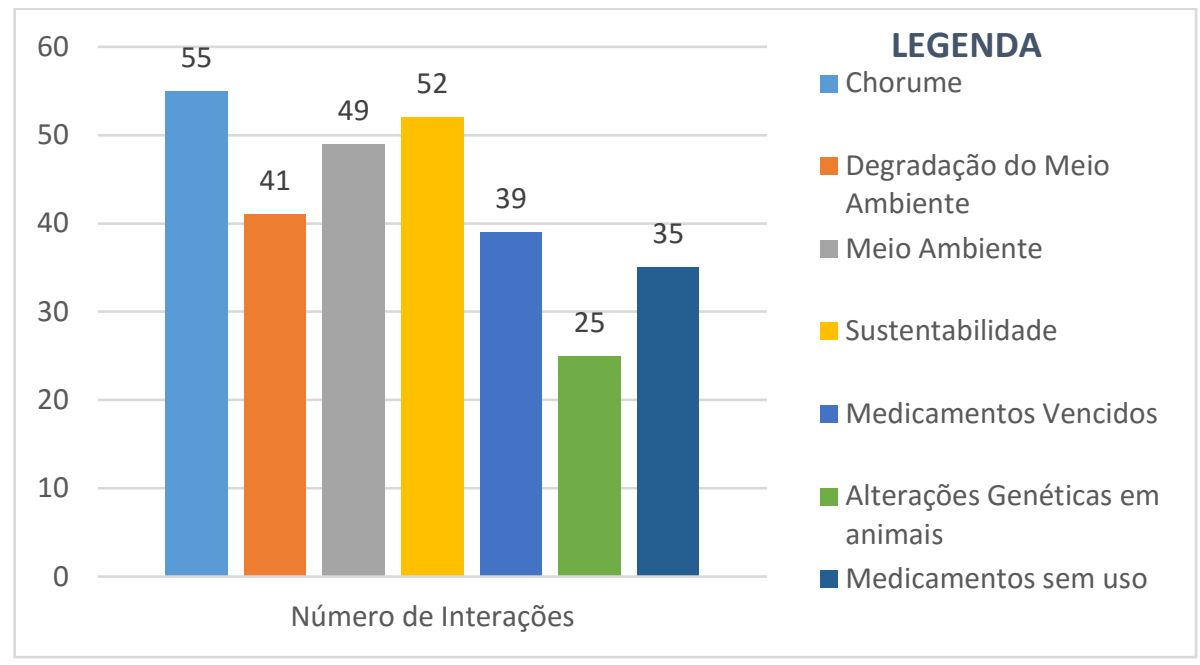

Figura 1. Tópicos de Discussões mais Promovidas.

Observa-se que os tópicos mais discutidos Chorume e Sustentabilidade obtiveram o maior número de posts, acima de 50 interações no quadro colaborativo, isto demonstra, o interesse dos estudantes em discutirem esses dois temas. Entre 30 e 50 posts temos os tópicos Meio Ambiente, Degradação do Meio Ambiente, Medicamentos Vencidos e Medicamentos em uso, estes por sua vez, também foram difundidas e potencializadas suas causas, danos ou fatores. Com menos de 30 posts temos o tópico Alterações Genéticas em Animais, uma discussão emergente, mas que não obteve tanto repercussão devido ao material escasso sobre o assunto na $W e b$.

Ainda, através dos posts e das discussões, que os aprendizes alimentavam na ferramenta, era possível verificar a construção do conhecimento [GALIAZZI et al, 2004] de forma coletiva [LÉVY, 2003] [BEDIN et al., 2014], onde um estudante contribuía na aprendizagem do outro dialogando os resultados inerentes de suas próprias descobertas e agregando ao coletivo. Temos nas reflexões de Maturana (1997) uma sintetização dessa ação, quando o mesmo, fala:

[...] o educar se constitui no processo em que a criança ou o adulto convive com o outro e, ao conviver com o outro, se transforma espontaneamente, de maneira que seu modo de viver se faz progressivamente mais congruente com o do outro no espaço de convivência. O educar ocorre, portanto, todo o tempo e de maneira recíproca. [...]. A educação como "sistema educacional" configura um mundo, e os educandos confirmam em seu viver o mundo que viveu em sua educação (MATURANA, 1997).

A oficina PAE, também proporcionou, o levantamento da ciência da necessidade do descarte correto dos medicamentos pela população que convive com os educandos. Os estudantes foram instruídos a coletarem informações em suas comunidades, nas suas famílias e círculos de amizades. A pesquisa apresentou um universo de 100 pessoas adultas, entre a faixa etária de 25 a 75 anos, que vivem em situação de vulnerabilidade social, utilizou-se a técnica de entrevista. Dessa pesquisa obtivemos os seguintes resultados registrados na Figura 2 abaixo. 


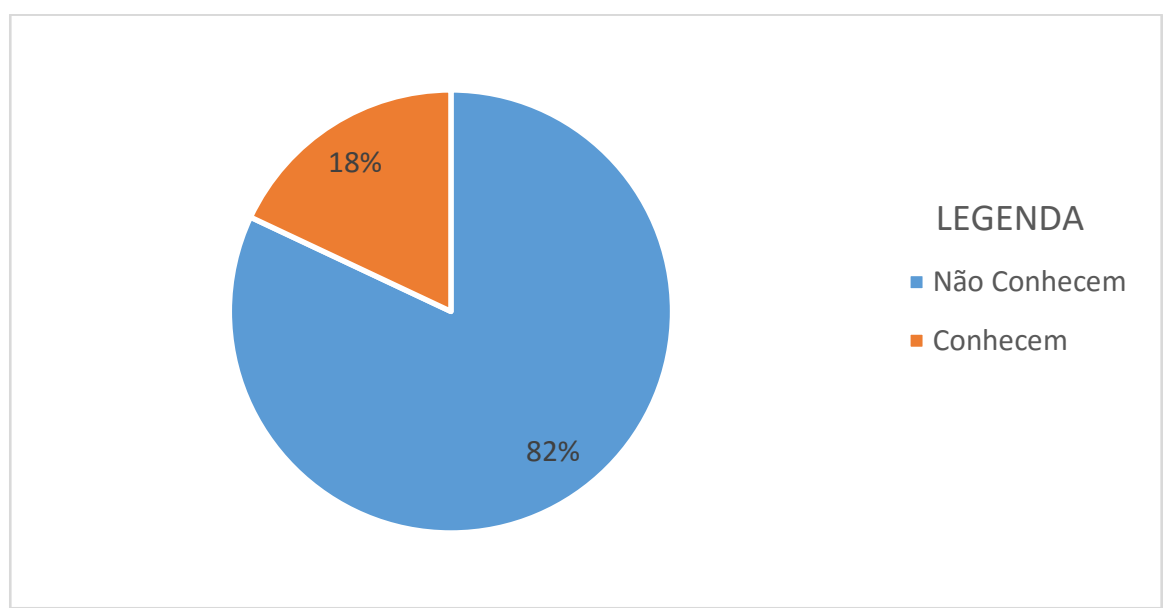

Figura 2. Conhecimento do Descarte Correto de Medicamentos.

\section{Considerações Finais}

Este artigo buscou investigar de que forma ocorreu o desenvolvimento de um Projeto de Ação na Escola que tinha como objetivo principal tratar os problemas originados pelo descarte de medicamentos, adotando como metodologia, de abordagem construtivista, as Unidades de Aprendizagem, na qual os estudantes desenvolveram os conhecimentos referentes ao conteúdo abordado, além de, tornarem-se conscientes dos problemas ambientais ocasionados pelo mesmo, assim como, utilizarem-se das tecnologias da informação e comunicação para o desenvolvimento de quadros colaborativos online.

Embasados de uma metodologia construtivista de ensino e aprendizagem, foi possível traçar um cenário onde que potencializasse a construção de conhecimento dos estudantes, de forma que, a inteligência coletiva permeasse através dos campos férteis do ciberespaço. Os conhecimentos prévios de cada aprendiz não foram desconsiderados, permitindo que, as vivências individuais, assim como, as considerações através de suas próprias buscas fossem compartilhadas para o coletivo, de modo que, a cibercultura proporcionasse esse elo de ensino e aprendizagem tão emergente em nossa contemporaneidade.

O impacto na vivência dos estudantes ao construírem seus conhecimentos sobre o agir sustentável foi perceptível no número de interações nos quadros colaborativos, na fala, escrita e diálogo dos aprendizes, que culminou, na propriedade com que os mesmos discursaram na apresentação realizada para toda a escola. Confirmando, desta forma, em seus viveres o mundo que viveram na construção de seus conhecimentos. Também norteamos tal impacto de vivência na forma intrínseca que se dá a Educação Ambiental permitindo o debate acadêmico de forma interdisciplinar e nas mais diversas áreas do conhecimento.

Por fim, é relevante ressaltar que, ainda os estudantes que possuíram alguma dificuldade nos diálogos e debates realizados no ambiente educativo, devido a timidez ou problemas de disfemia, estes, encontraram nos quadros online uma forma de contribuírem com seus conhecimentos e ideias para a coletividade. Desta forma, os objetivos traçados na construção do Projeto de Ação da Escola e, por conseguinte, desta pesquisa foram alcançados com o subsídio das Tecnologias da Informação e Comunicação, e a supracitada, oportunizou que: os aprendizes tornassem autores da construção de seu conhecimento, desenvolvendo suas atividades alicerçados na inteligência coletiva, 
V Congresso Brasileiro de Informática na Educação (CBIE 2016)

Anais do XXII Workshop de Informática na Escola (WIE 2016)

utilizassem o ciberespaço realizando trocas sociais, colaborando assim, para a apropriação da cibercultura, desenvolvessem seus conhecimentos baseados nos conhecimentos prévios de cada indivíduo e se tornassem conscientes ambientais do problema exposto, multiplicando, sua própria consciência através de sua vivência.

\section{Referencias}

BEDIN, E.; BARWALDT, R. Tecnologia da Informação e Comunicação no contexto escolar: interações à luz da sustentabilidade ambiental no viés das redes sociais. RENOTE. Revista Novas Tecnologias na Educação, v. 12, p. 1-10, 2014.

BRASIL. Lei n ${ }^{\circ}$ 12.305, de 2 de agosto de 2010. Brasília, DF: [s.n], 2010. Disponível em: $<$ http://www.planalto.gov.br/ccivil_03/_ato2007-2010/2010/1ei/112305.htm>. Acesso em: 18 abr. 2016.

CELIO, S; MEIRA, C. D; AMORIM, M. F. da S. J. Educação ambiental: ação integradora na formação de cidadãos críticos em seus contextos de vida. Revista Eletrônica do Mestrado Em Educação Ambiental, Rio Grande, ed. Especial, p.223230, jun 2015.

COSTA, A.C.R. (2005). A Teoria Piagetiana das Trocas Sociais e sua Aplicação aos Ambientes de Ensino-aprendizagem. Em: Informática na Educação: Teoria \& Prática. 06(02)

GALIAZZI, M. C.; GARCIA, F. Á.; LINDEMANN, R. H. Construindo Caleidoscópios - organizando unidades de aprendizagem. In: MORAES, R.; MANCUSO, R. Educação em Ciências - produção de currículos e formação de professores. Ijuí: Unijuí, 2004. p. 65-84.

GIL, A. C.. Como elaborar projetos de pesquisa. 4. ed. São Paulo: Atlas, 2008.

http://www.imshealth.com. Acesso em: 24 mar. 2016.

https://padlet.com/ - Acesso em: 12 mar. 2016.

LÉVY, P. A inteligência coletiva: por uma antropologia do ciberespaço. 4.ed. São Paulo: Loyola, 2003.

MARQUEZOTI, Nerly; DE BITENCOURT, Rafael Mariano. DESCARTE DE MEDICAMENTOS, RESPONSABILIDADE DE TODOS. Unoesc \& Ciência-ACBS, v. 7, n. 1, p. 47-54, 2016.

MATURANA, R. H.. De máquinas e seres vivos: autopoiése - a organização do vivo. Porto Alegre: Artes Médicas, 1997.

MORAES, R., GALIAZZI, M.C. E RAMOS, M.G. (2004). Pesquisa em sala de aula: fundamentos e pressupostos. En Moraes, R. e Lima, V.M.R. (Orgs.). Pesquisa em Sala de Aula: tendências para a Educação em Novos Tempos (pp. 9-24). 2. ed. Porto Alegre: EDIPUCRS.

REIGOTA, M. A. dos S.. Ciência e sustentabilidade: a contribuição da Educação Ambiental. 2007. 232f. Dissertação (mestrado em Educação). Universidade de Sorocaba: São Paulo, 2003. Disponível em: $<$ http://www.scielo.br/pdf/aval/v12n2/a03v12n2.pdf>. Acesso em: 18 abr. 2016. 